Article

\title{
Towards 3D Cadastre in Serbia: Development of Serbian Cadastral Domain Model
}

\author{
Aleksandra Radulović * (D), Dubravka Sladić and Miro Govedarica \\ Faculty of Technical Sciences, University of Novi Sad, 21000 Novi Sad, Serbia; dudab@uns.ac.rs (D.S.); \\ miro@uns.ac.rs (M.G.) \\ * Correspondence: sanjica@uns.ac.rs; Tel.: +381-63-102-8536
}

Received: 29 August 2017; Accepted: 16 October 2017; Published: 19 October 2017

\begin{abstract}
This paper proposes a Serbian cadastral domain model as the country profile for the real estate cadastre, based on the Land Administration Domain Model (LADM), defined within ISO 19152. National laws and other legal acts were analyzed and the incorrect applications of the law are outlined. The national "Strategy of measures and activities for increasing the quality of services in the field of geospatial data and registration of real property rights in the official state records", which was adopted in 2017, cites the shortcomings of the existing cadastral information system. The proposed profile can solve several problems with the system, such as the lack of interoperability, mismatch of graphic and alphanumeric data, and lack of an integrated cadastral information system. Based on the existing data, the basic concepts of the Serbian cadastre were extracted and the applicability of LADM was tested on an obtained conceptual model. Upon obtaining positive results, a complete country profile was developed according to valid national laws and rulebooks. A table of mappings of LADM classes and country profile classes is presented in this paper, together with an analysis of the conformance level. The proposed Serbian country profile is completely conformant at the medium level and on several high-level classes. LADM also provides support for three-dimensional (3D) representations and 3D registration of rights, so the creation of a country profile for Serbia is a starting point toward a 3D cadastre. Given the existence of buildings with overlapping rights and restrictions in $3 \mathrm{D}$, considering expanding the spatial profile with 3D geometries is necessary. Possible solutions to these situations were analyzed. Since the two-dimensional (2D) cadastre in Serbia is not fully formed, the proposed solution is to use the 2D model for simple right situations, and the 3D model for more complex situations.
\end{abstract}

Keywords: LADM; Serbian country profile; 3D cadastre

\section{Introduction}

The term "land administration" refers to "the processes of determining, recording, and disseminating information about the ownership, value, and use of land when implementing land management policies" [1]. Land administration functions may be divided into four components: juridical, regulatory, fiscal, and information management. The juridical component focuses on registration of rights on immovable properties, the regulatory component is mostly concerned with the development and use of land, the fiscal component focuses on the economic utility of properties and supports their valuation and taxation, and the information management component focuses on the development of land information systems [2]. The core of land administration is the cadastral system, which identifies legal boundaries of cadastral parcels through geodetic survey and produces cadastral maps and, at least in our case, records legal rights on properties.

Well-structured and organized cadastral records and cadastral maps are a prerequisite for providing better services in land administration. Many problems have occurred related to the collection 
and maintenance of cadastral data in Serbia and attempts have been made to overcome these issues. However, one of the main problems still remains and that problem is related to the way in which data are organized and maintained, which affects the data integrity causing an inability to address user needs in a timely manner [3]. The Serbian cadastre consists of two parts: Cadastral records that represent the legal relationship between people and real properties, and the cadastral maps that, beside geometry data and annotations, contain land use components visualized by topographic symbols.

Cadastral records in Serbia have encountered numerous problems in previous years, such as the existence of different institutions responsible for the management of land data and real properties, storing data in multiple places, data storage in analog form, discrepancy in records in relation to the actual situation, separation of alphanumeric and geometric data, complex structure of the records as a result of inheriting data from different sources, poor performance of search and update of data, and lack of a standard format for data exchange. Some of the problems have been resolved but many have not. Problems relating to the lack of uniformity of the data model, as well as to the use of non-relational data model, exist in all municipalities in Serbia. Other problems are related to the use of different software solutions, which are mainly based on outdated technologies, and the use of the concept of immovable property in software solutions as defined by outdated law. The aforementioned problems can lead to data redundancy, re-implementing functionality, and disturbed correctness of the data.

The data model is the core of the system. To avoid problems and to achieve efficient access, sharing, and exchange of cadastral data on the principles of interoperability, creating a domain model according to national legislation and current standards in the field of geospatial data and cadastre is necessary, particularly for the Land Administration Domain Model (LADM) within ISO 19152 [4].

This research was motivated by the problems that have arisen in the Serbian land administration due to the inadequate legacy cadastral information system. Specifically, there is a need in the Serbian cadastre to develop a new system based on a new data model that will support better cadastral data management, provide better integrity of data by establishing relations among data, and enable more advanced search of the data. For example, a user is not able to perform a search to retrieve all the rights of a certain party, so this functionality must be provided. In addition, serious cadastral data integrity problems that are present should be addressed in the modeling phase of the cadastral information system development. Legal data, which are textual, and surveying data, which are mainly spatial, are usually hard to maintain in a consistent state. The source of the problem is because those two parts of the same land administration system were modeled independently.

The aim of this research was to develop a domain model for the Serbian cadastre, with the purpose of developing a model that will support the resolution of the mentioned problems. The model should be based on the LADM $[5,6]$ to provide interoperability and better data quality. A roadmap to adopt the LADM in the cadastral information system has been provided in Kalantari et al. [7], through several stages that should be considered by land administration organizations, in this case, the Serbian Republic Geodetic Authority. The developed domain model will then be proposed as a country profile.

The aim was also to analyze the needs and possibilities for the development of a three-dimensional (3D) cadastre [8] in Serbia, based on current research and development trends [9]. The main idea behind this is that, since a big gap exists between current cadastral information organization in Serbia and current research and technology trends, and the need for change is significant, the cadastre should not be limited to what is currently recorded in the information system, but also to anticipate future requirements. This idea is supported by the fact that there is an increasing use of modern technologies for 3D data acquisition in Serbia, such as photogrammetry, LIDAR, terrestrial laser scanning, and a number of 3D models in CityGML, and other formats for parts of the cities, developed for various purposes and for various organizations, that may provide input for 3D rights registration.

Several country profiles based on a LADM have been proposed including Poland [10], Czech Republic [11], and Croatia [12,13]. The model-driven architecture (MDA) approach can be used to automatically implement the database schema, which can be then put into use by a country [14]. In addition, several initiatives concerning the development of a 3D cadastre are ongoing, including: 
the development of a 3D cadastre in The Netherlands [15], a transition from two-dimensional (2D) to 3D cadastre in Slovenia [16], and the extension of the Korean LADM country profile to build a 3D cadastre model [17].

This paper presents a domain model of the Serbian cadastre to propose a LADM-based country profile with the goals of ensuring that the LADM-based country profile reflects the current cadastral registration and the corresponding legal requirements, and to determine the conformance between the proposed Serbian country profile and the LADM, and to determine if an extension into a 3D cadastre is possible.

This paper is divided into four sections. Section 1 is the introduction, in which the motivation and aim of this research is described. Section 2 describes the cadastral information system in Serbia that is currently in use, and emphasizes the need for its improvement. Section 3 presents how to transform data model that is currently in use into a LADM-based domain model for the Serbian cadastre that the authors propose for the country profile. Section 4 presents the research toward the development of a 3D cadastre in Serbia. Conclusions and future work are given afterward.

\section{Cadastral Information System in Serbia}

The cadastral information system in Serbia is regulated by the Law on State Survey and Cadastre from 2009 [18] ("the Law"), Amendments to the Law in 2015 [19], and the Rulebook on Cadastre Survey and Real Estate Cadastre from 2016 [20]. The Law defines the real estate cadastre as a basic and public register of real properties and the rights to those properties. Real properties that are recorded in the cadastre are divided into: Land (cadastral parcel), ground and underground buildings and separate parts of the buildings that make one structural units, such as apartments, business offices, garages, etc. "Buildings" refer to residential buildings, commercial buildings, cultural objects, sports and recreation, roads, bridges, underground passages, dams, embankments, and others. The data on the underground buildings are connected to the parcel where the main entrance or one of the entrances to the underground building is located. The utility network cadastre is the main register of the lines and rights to them, together with the property owner's rights, and contains information on the following: water supply network, sewage and drainage network, hot water network, electricity network, telecommunications network, pipeline network, gas pipeline network, and common facilities. Article 157 of the Law states the necessity for implementing a unified information system of both the real estate cadastre and the utility network cadastre, but this has not yet been achieved.

In the information system of the real estate cadastre, alphanumeric data are separated from graphic (spatial) data. Geographical information systems (GIS) and Computer Aided Design (CAD) tools are used for the transformation of analog cadastral maps into digital vector format. Ninety percent of cadastral municipalities are digitized [21]. After digitization, the topological and geometric consistency of the content of the digital cadastral map are tested by checking the fulfillment of the rules for creating geometric and topological relationships between objects. The alphanumeric parts of the information system for real properties in Serbia were implemented in a DOS application, based on FoxDbf tables for a significant part of Serbian territory, while a small part of data is stored in a Microsoft Access database. Data models in these two applications differ from each other, with an evident absence of relationships in the FoxDbf database. The data model is based on the real estate folio concept, a legacy paper document that consists of four sheets. Figure 1 displays the database tables that represent the four sheets with the most important attributes. Other attributes are omitted from the figure for better visibility. The " $\mathrm{A}$ " sheet contains data about one or more parcels. The " $\mathrm{B}$ " sheet contains data about parties which have rights over parcels from the A sheet. The "V" sheet contains data about buildings and parts of buildings, such as apartments and business offices, which are located in parcels listed in the A sheet, together with data about their rights. The "G" sheet contains data about restrictions on real properties defined in the A and V sheets. This is how the Law on State Survey and Cadastre and the Registration of Rights on Real Estates Cadastre (1992) [22] are defined in 
the real estate folio. However, the current Law defines a real estate folio as data about a single real property together with its rights and restrictions.

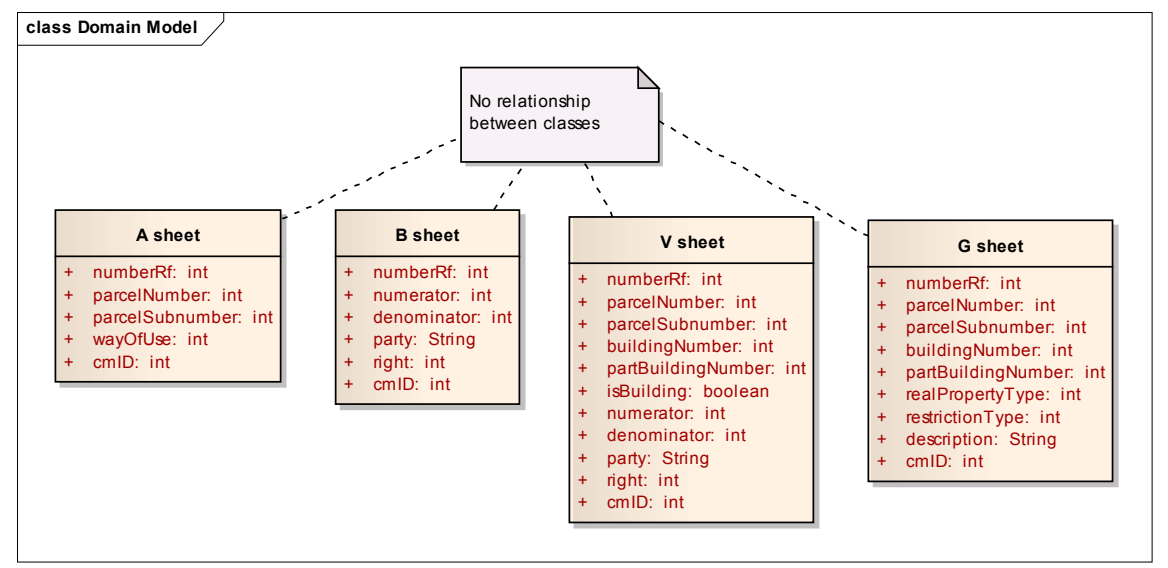

Figure 1. Existing data model.

In January 2017, “The Strategy of measures and activities for increasing the quality of services in the field of geospatial data and registration of real property rights in the official state records" [22] ("the Strategy") was adopted. It contains measures to achieve the implementation of the plan by 2020. The Strategy analyzes the existing state of the cadastral system and lists the following weaknesses in terms of access and use of spatial data in the Republic of Serbia: Unclear data, mismatch of data, the heterogeneity of the information technology systems, multiplication of effort and costs, insufficient use of standards, lack of appropriate digital data, lack of interoperability, poor reliability and confidentiality of data, unclear quality of data, mismatch of graphic and alphanumeric data, and lack of an integrated cadastral information system. The Strategy recognizes the INSPIRE Directive [23] and ISO 19152 standard as world trends in geodetic science that need to be followed and applied. Several attempts to develop a new cadastral information system in Serbia have been made in past years, but those projects failed due to bureaucratic reasons. A new project is underway and it should implement all measures mentioned in the Strategy.

Based on the above, and given the development of information technology, a need exists to improve the current cadastral system and to integrate existing subsystems (alphanumeric and graphical, as well as the utility network subsystem) into one unifying data model that will be completely based on current legislation and standards in the field of spatial data and land administration. According to "the Strategy of establishing a spatial data infrastructure in the Republic of Serbia" [24], the national data infrastructure should be established in accordance with the principles set out in the INSPIRE Directive. The INSPIRE Directive states that all the rules for its implementation should consider the standards that have been developed by the international standardization bodies. Since the cadastral data are part of the spatial data infrastructure, the domain model for the cadastre should be based on the domain model for land administration (LADM) defined within the ISO 19152 standard and the national legislation.

\section{Serbian Country Profile for the Real Estate Cadastre}

Research was performed using the following steps: analysis of the requirements defined in the Law and the Strategy; analysis of the international standards in the field of research and literature review; analysis of the current cadastral information system, its data dictionary, and data sets; reverse engineering for to transform the physical model to a logical model; and conceptual modeling to capture concepts in the cadastral domain with the aim of developing a standardized domain model. 


\subsection{Conceptual Model of the Serbian Real Estate Cadastre}

The first step in creating a new domain model was the formation of a conceptual model of the real estate cadastre for Serbia. In the current database schema, real properties, rights, and restrictions are grouped by sheet as listed in the real estate folio document, defined by the Law in 1992. Figure 2 shows a conceptual model that represents the contents of A sheet. The A sheet contains data about parcels and parts of parcels, which represent different types of land use within one parcel. Basic attributes for a parcel are the number of the parcel, cadastral municipality, and the number of the real estate folio. According to this, a conceptual model was derived and including the classes of CadastralMunicipality, Parcel, PartOfParcel, and RealEstateFolio. A cadastral municipality is formed as a collection of a certain number of parcels within which the numbers of the parcels range from 1 to $n$. A cadastral municipality is a territorial unit in which the cadastral survey was completed, covering the area of one city or a village. It is also possible that several villages belong to one cadastral municipality or that parts of one city are in several cadastral municipalities. Parcels are recorded within the real estate folio so that one folio can contain several parcels. A cadastral parcel is a basic cadastral territorial unit and represents a part of the land in the cadastral municipality defined by the border and marked by a unique number on which exists an ownership right.

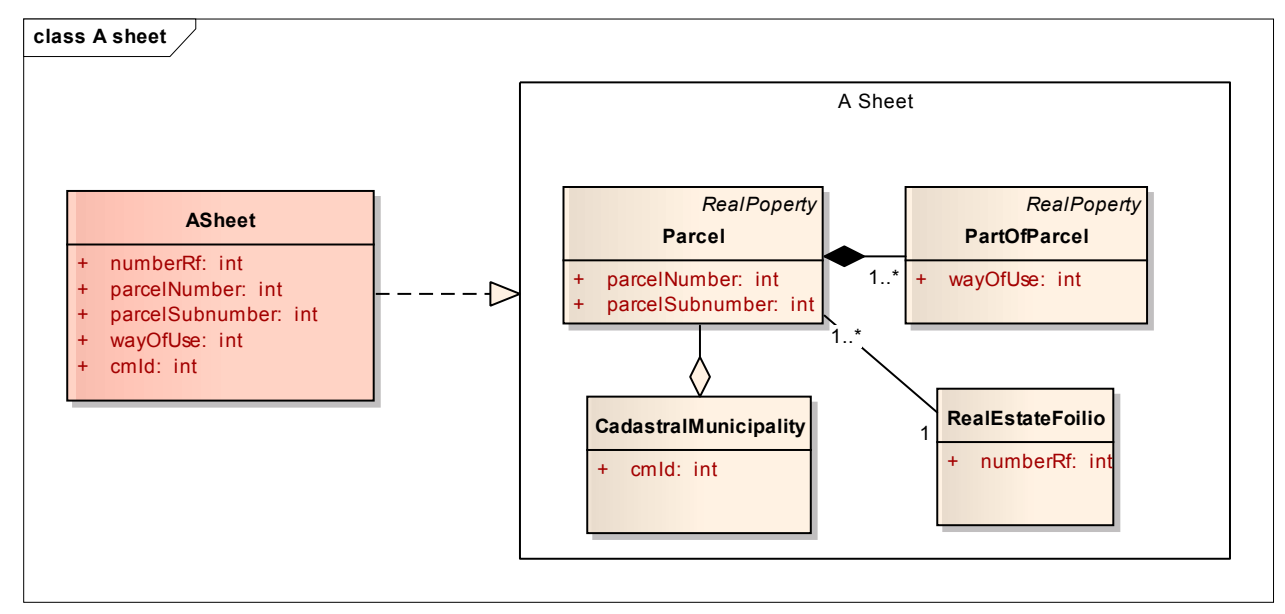

Figure 2. Transformation of the " $\mathrm{A}$ " sheet class.

In a similar manner, the other classes in Figure 1 were transformed into the conceptual model. The B sheet was transformed into the classes Party and RightsOverParcel. Party refers to the records of natural and legal parties who have some rights over real properties. RightsOverParcel refers to a specific right bringing together a party, the type of the right, and share of the right, as well as the number of the real estate folio. The $\mathrm{V}$ sheet contains data on buildings and parts of buildings together with information about rights to them. A building is identified by a number and the corresponding parcel. This leads to the following classes: Building, PartOfBuilding, and RightsOverBuildingAndPart, which is the rights on a building and its parts. The $G$ sheet contains data about restrictions on real properties. The Restriction class was created for this purpose. Afterward, a generalization of the conceptual model was performed by introducing two abstract classes: RealProperty, representing all three types of real properties, and Rights, which represents the rights on any type of real property.

Finally, the domain model of the real estate cadastre in Serbia was represented as shown in Figure 3. The real estate folio contains one or more real properties from the A and V sheets, one or more rights to the real properties from the $\mathrm{B}$ and $\mathrm{V}$ sheets, and either no or more restrictions on the real property from the $\mathrm{G}$ sheet. One party may have zero or more property rights. 


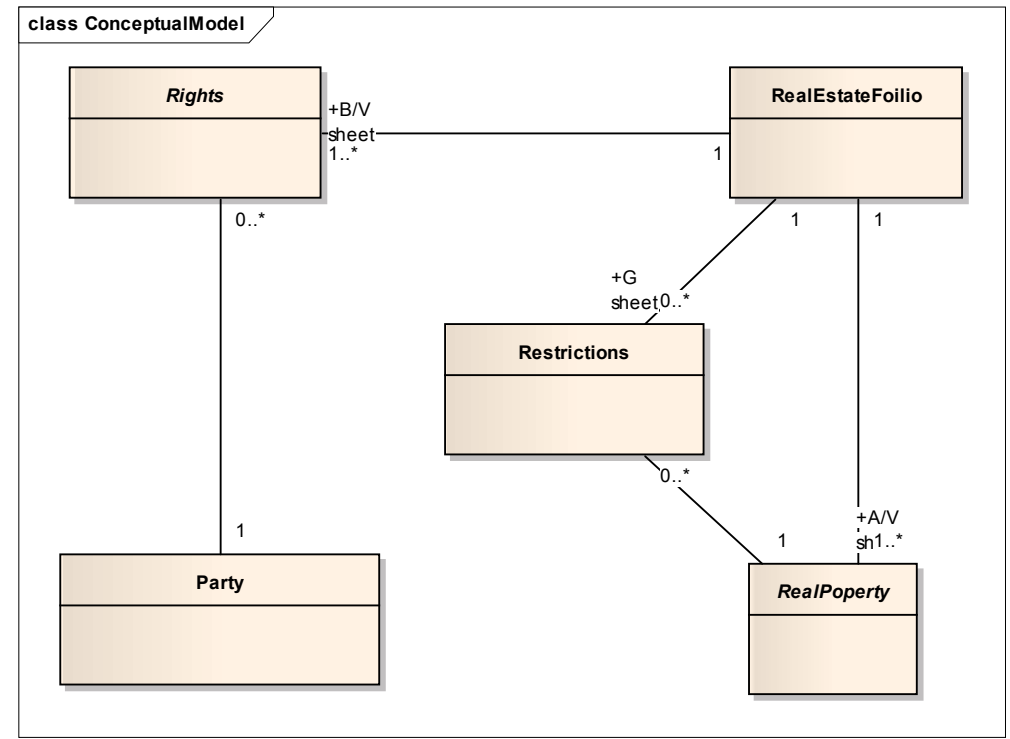

Figure 3. The basic schema of the conceptual model for Serbia.

This model describes the current data structure that is formed under the Law from 1992. According to the Law from 2009, a real estate folio contains a single real property with its rights and restrictions. This affects the previous model by changing the multiplicity on class RealProperty from $1 .{ }^{*}$ to 1 .

\subsection{Serbian Country Profile for Land Administration}

The second step in the establishment of the standardized domain model was to analyze the possibilities of fitting the resulting conceptual model in LADM $[25,26]$. Figure 4 shows the mapping of the basic LADM classes into the Serbian conceptual model classes [27].

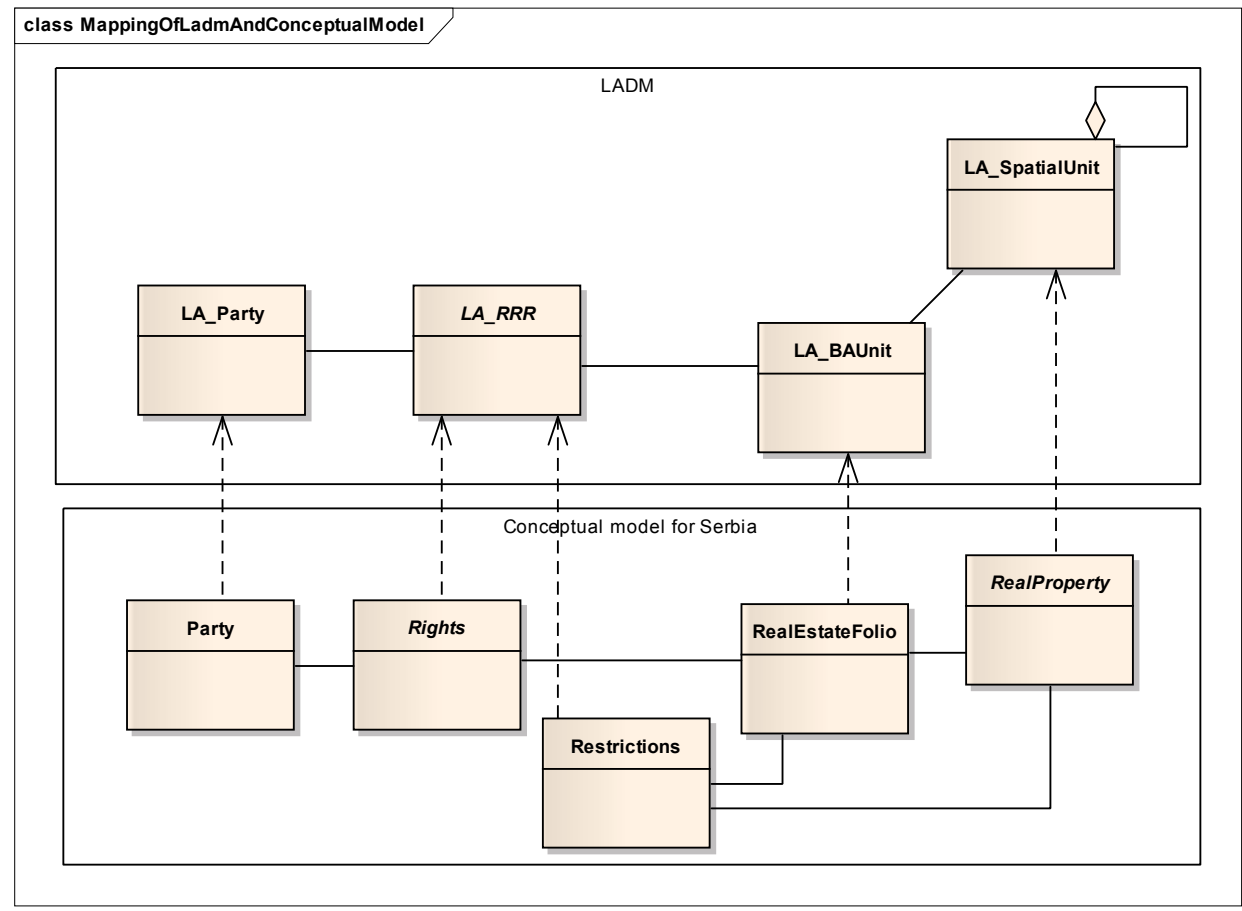

Figure 4. Mapping of basic classes in the Serbian data model to the Land Administration Domain Model (LADM) classes. 
Since the LA_Party class describes the right holders, the appropriate class of the conceptual model is the Party class. LA_SpatialUnit describes spatial units, meaning real properties like parcel, building, and part of building, and were mapped to the abstract class RealProperty. LA_RRR describes the rights, restrictions, and responsibilities over a real property. In the conceptual model, two classes were created to describe the rights and restrictions, Rights and Restrictions, and both were derived from the LA_RRR class. The LA_BAUnit class represents a basic administrative unit, which is a set of rights, restrictions, and responsibilities of one or more real properties so that the sum of shares is equal to one. In the conceptual model for Serbia, this is equivalent to the real estate folio, so the corresponding class is RealEstateFolio.

Since the applicability of basic LADM on the Serbian conceptual model has been proven, it was possible to create basic classes corresponding to the Serbian profile (Figure 5). All classes from the Serbian country profile have the prefix RS. The Law defines a real estate folio as data on one real property together with its rights and restrictions. By analyzing the association between RS_SpatialUnit and RS_BAUnit, we concluded that with the current legislation, the cardinality of connection should be one to one. With this change, we accomplished a maximum of one real property being defined in one real estate folio.

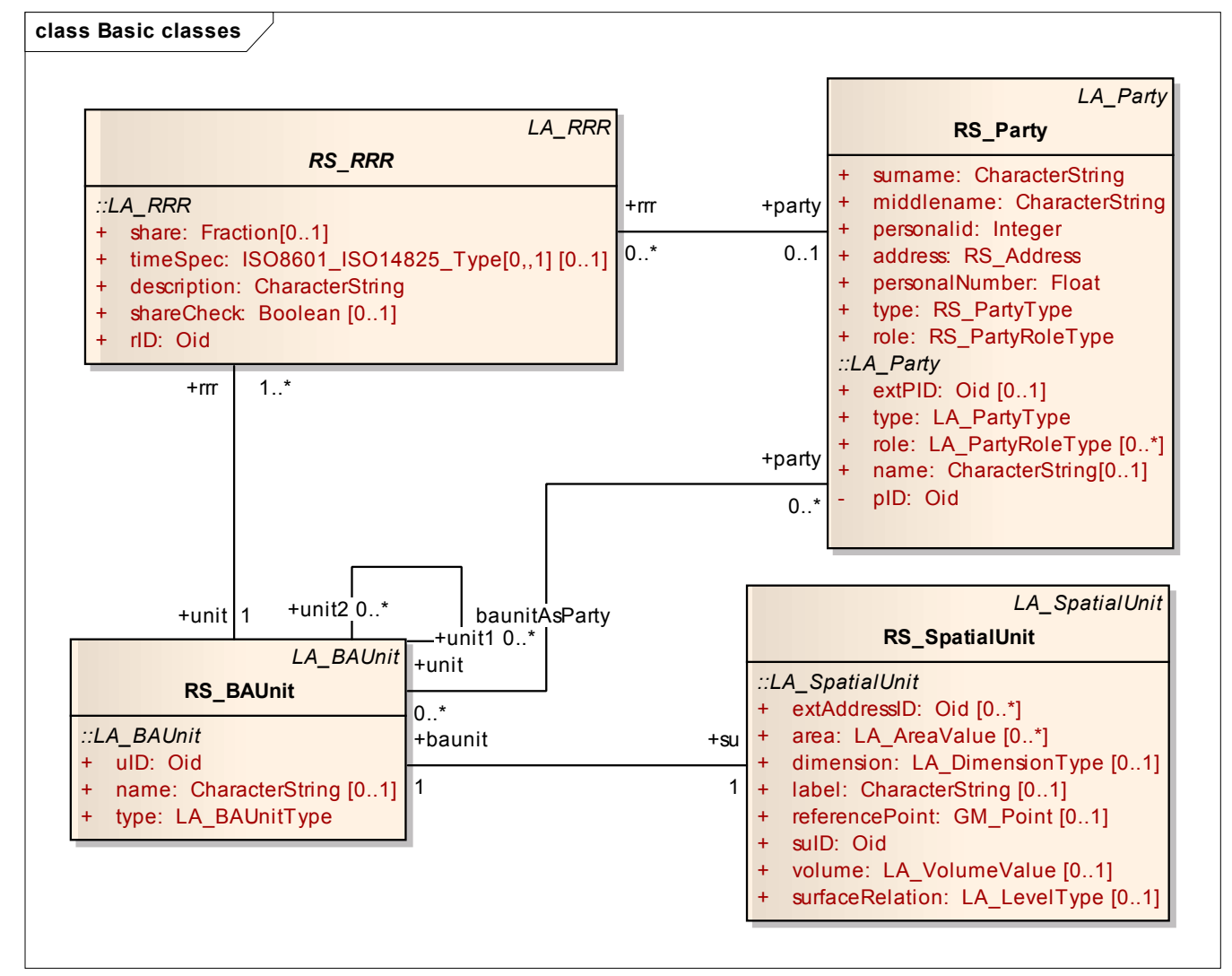

Figure 5. Basic classes in the Serbian profile.

Figures 5-7, 10 and 14 contain a complete country profile for Serbia, followed by instance diagrams (Figures 8, 9, 12, 13 and 19) with examples for characteristic situations. Classes for every package and subpackage are displayed together with code lists. The VersionedObject class was used in the development of country profile to manage and maintain historical data. Inserted and superseded data are given a time-stamp. In this way, the contents of the database could be reconstructed as they were at any historical moment. In the following diagrams, this class will not be shown to save space. 


\subsubsection{Party Package}

The basic class in the Party package is RS_Party, used to describe holders of rights in the cadastral system (Figure 6). In the code list, RS_PartyType refers to the basic administrative unit ("baunit"), group, natural persons, and non-natural persons. In the code list, RS_PartyRoleType includes all the various roles, such as state agency, citizen, notary, etc. Additional attributes in the class RS_Owner are surname, middle name, address, personal identification (personalid), and ID card number (personalNumber). The class RS_GroupParty is a group party which can be "baunit", an association, or a family (RS_GroupPartyType). Group party is used, for example, in a common ownership on the real property in which several parties have the same right with an indefinite share so they act as one party.

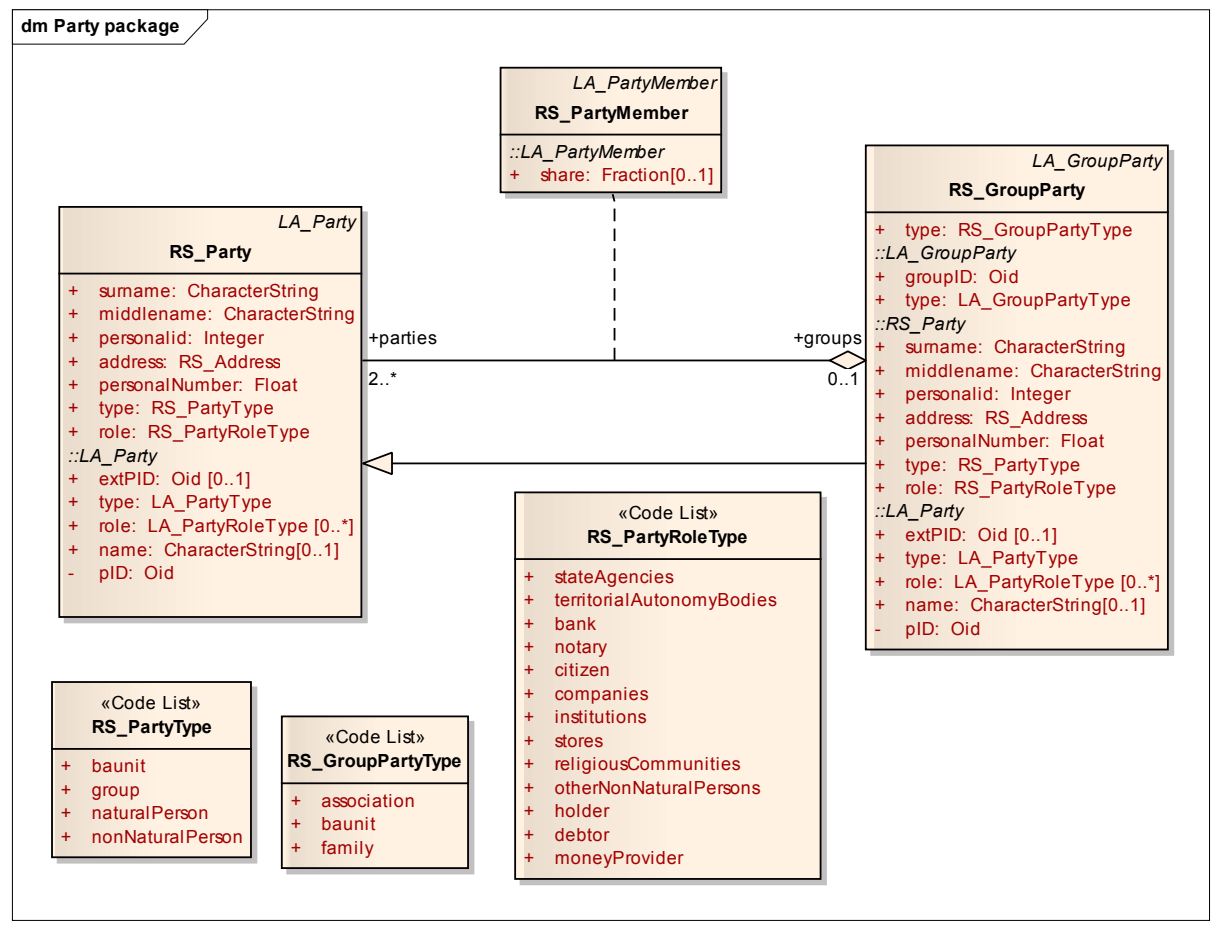

Figure 6. Party package of the Serbian profile.

\subsubsection{Administrative Package}

Rights, restrictions, "baunits", and administrative sources are defined within the administrative package (Figure 7). RS_RRR defines an abstract class that represents the rights, restrictions and responsibilities, and subclasses RS_Restriction and RS_Right as a such as of this class. The Serbian cadastre does not maintain data about responsibilities like monument maintenance, cleaning a ditch, keeping a snow-free pavement, etc. Such responsibilities are defined within the "Decision on the communal order" for every city itself and are handled by public utility companies, other legal entities, entrepreneurs, and natural persons. To introduce the class LA_Responsibility into the profile, the Law would need to be changed and would require long-term data recording of responsibilities for each real property, so this class will remain outside of the profile. Rights are described by the share and type of the right, which can include ownership, right to use, lease, etc. To describe the type of a share, including a whole right, ideal part, real part, or common, the code list RS_RightShareType was added. The attribute Ownership shows whether a right is an ownership or not. If it is, a type of ownership is selected from the code list RS_OwnershipType (private, public, social, etc.). 


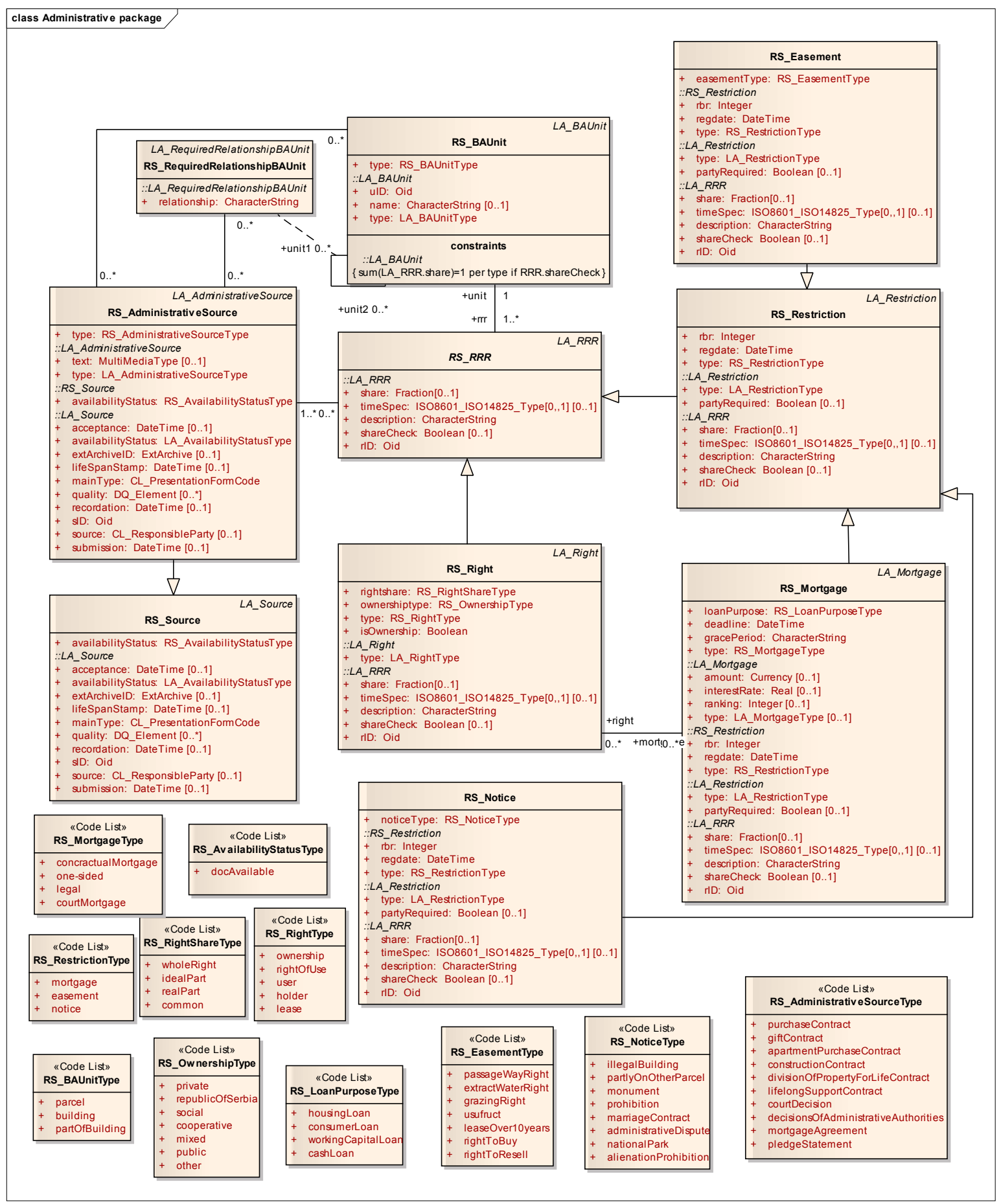

Figure 7. Administrative package of the Serbian profile.

The Law on Property Relations in Serbia [28] recognizes the concept of common ownership, which is an ownership of two or more parties whose shares in the ownership are not determined nor can, as a rule, be alienated while the joint property regime is in place. In addition, for the common parts of the building, such as elevators, roof, attic, stairs, and corridors, owners of apartments, garages, and business offices have the right of common indivisible ownership. Owners of apartments and special parts of the building have the right to use common parts of the building according to their purpose, regardless of the size of their particular part of the building. Such situations are recorded in the Serbian cadastre as common ownership without a defined share of the right. Persons who have common 
ownership act as a group and can only sell their real property by a common agreement. In the event that an agreement cannot be reached, the division of property is carried out by a court procedure. Figure 8 shows an example of the common ownership of a vineyard by two persons. Class RS_Parcel relates to a spatial unit and is explained in the Section 3.2.3.

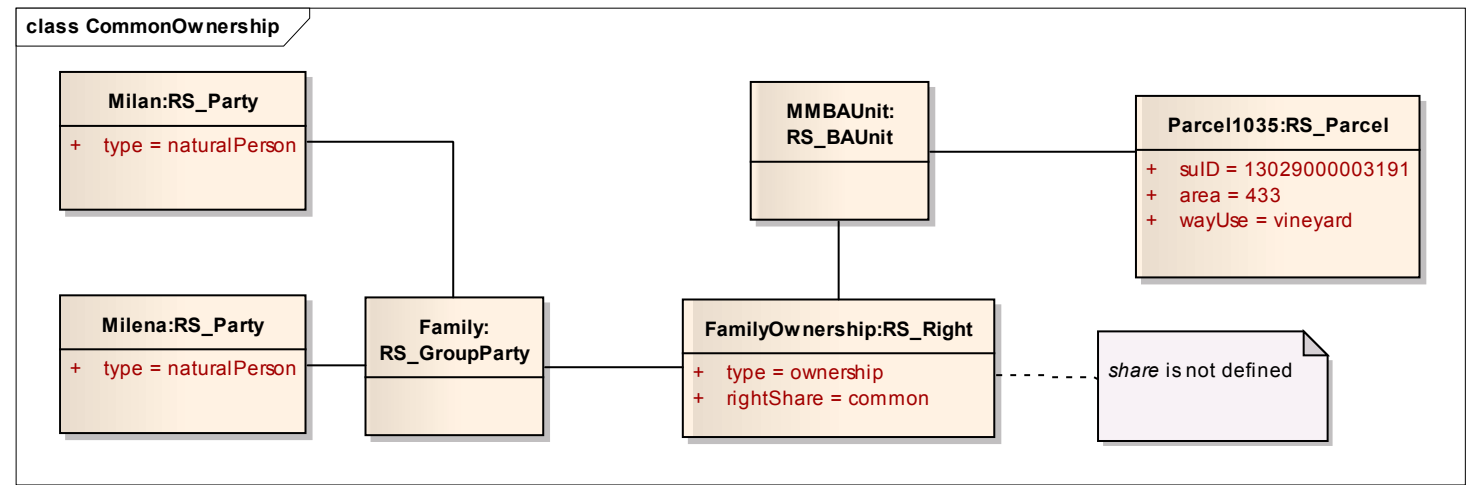

Figure 8. Instance diagram of a common ownership of a vineyard.

Restrictions on real properties in Serbian cadastre are described with ordinal number, description and a type. There are three types of restrictions, mortgages, easements and notices, and therefore three classes, i.e. RS_Mortgage, RS_Easement and RS_Notice.

A mortgage is a special restriction of the ownership right. It involves conveying an interest in a property by a debtor to a creditor, as a security for a financial loan, with the condition that the property is returned, when the loan is paid off. To fully describe a mortgage, additional attributes for deadline registration and a grace period were added. The type of a mortgage is defined in the RS_MortgageType code list. The RS_LoanPurposeType code list contains values for different types of loan purposes. Figure 9 shows a mortgage on an ownership right with a party as the debtor and a bank as the creditor. The mortgage is verified by mortgage agreement created by the notary as a responsible party.

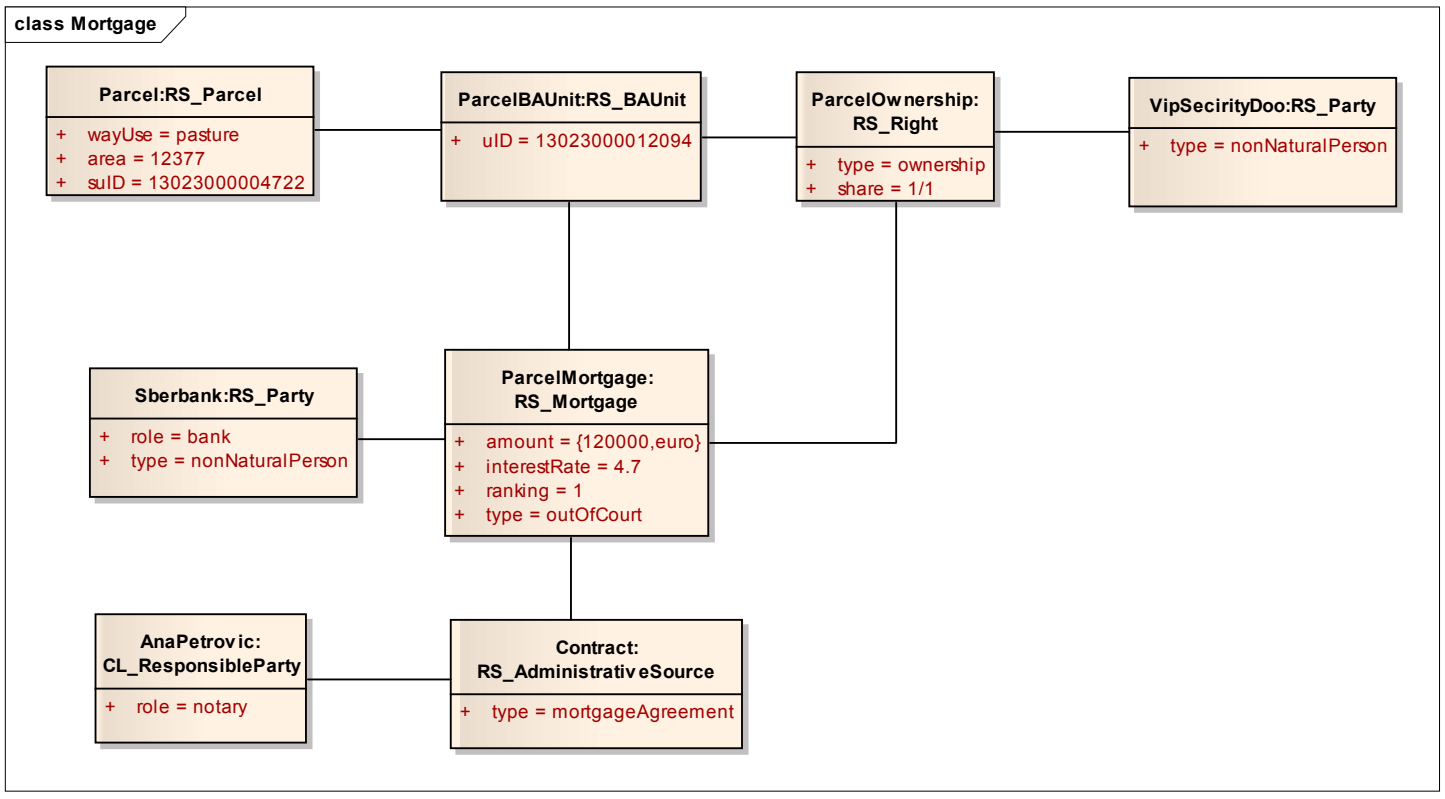

Figure 9. Instance diagram of mortgage on ownership. 
Easement is the right of the owner of a real property to use the neighboring real property in a certain way or to require the owner of the neighboring real property to keep from certain behavior. Easement is enrolled as usufruct, a right of passage, as well as other rights prescribed by the Law governing the rights to real properties. Easements are recorded on the real properties in favor of a particular right holder or for the benefit of another real property, regardless of the party with ownership right on that real property. Types of easement are defined in the RS_EasementType code list.

A notice relates to the registration of facts that are of importance for the establishment, modification, termination, or transfer of real rights to real properties, relating to the characteristics of the holder of the right, on the real property or on legal relations regarding the real property. The registration of a notice does not prevent further entries on the real property to which the registration refers. From the moment of registration of the notice, all registrations in the real estate cadastre of the holder, which are contrary to the purpose of the recorded notice, are conditional and depend on the outcome of settling the rights to the real property. Types of notices are defined in the RS_NoticeType code list. A notice is registered when a building is built without all necessary permits, or a part of building lies on another parcel, or when there is a marriage contract between parties, etc.

The RS_BAUnit class represents a set of rights and restrictions on real property so that the total sum of shares is equal to one. In the Serbian cadastre, the concept of "baunit" corresponds to a real estate folio. Since there are three types of real estate folio for parcels, buildings, and parts of buildings, the RS_BAUnitType code list has three corresponding values.

Registration of rights and restrictions on real properties is based on a private or public document, which states if the property is suitable for registration. Registration of real property rights is done on the basis of contract (purchase, gift, purchase of apartment, construction, division of property for life, lifelong support, etc.), court decisions (judgments and solutions), and decisions by the competent administrative bodies. Division of property for life is a special form of gift contract in which the ancestor can renounce and share their property according to their wishes. However, in order for this contract to be valid, all descendants who, according to the law, would be called upon to inherit the ancestry must agree and sign its contents. Registration of a mortgage is done on the basis of a mortgage contract, a pledge statement, or court decisions. These documents are described with the RS_AdministrativeSource class and the RS_AdministrativeSourceType code list.

\subsubsection{Spatial Unit Package}

Th spatial unit package is based on the RS_SpatialUnitGroup and RS_SpatialUnit classes (Figure 10). The RS_SpatialUnitGroup class is related to a set of spatial objects and can be used to specify the administrative units within the cadastral system, including country, administrative municipality, cadastral district, and cadastral municipality, which are defined in the RS_SpatialUnitGroupType code list.

The RS_SpatialUnit class describes spatial objects in the cadastre, including parcels, buildings, and parts of buildings, as well as utility networks, which are part of the utility network cadastre. A parcel is described by number and sub-number within one cadastral municipality (RS_Parcel). The type of land is determined by the RS_PuposeParcelType code list and refers to whether it is urban construction land, agricultural land, forest land, or public building land. One parcel may consist of several parts with different uses; hence, the RS_PartOfParcel is defined. Since rights and restrictions are defined over the entire parcel, part of the parcel class is a spatial unit within the partOfParcel level, while the parcels, buildings, and parts of the buildings are defined by the ownership level (RS_Level). The types of parcel use include field, garden, orchard, meadow, pasture, the land under the building, the city's green areas, embankments, a pond, an artificial lake, etc. (RS_WayOfUsePartParcel).

The RS_Building class that represents the building requires additional attributes to describe the number of the building, the date of construction, the number of entrances, number of floors underground, on the ground floor, above the ground, and in the attic, legal status (code list RS_LegalStatus), and the building use according to the RS_WayOfUseBuilding code list value 
(residential buildings, commercial buildings, auxiliary buildings, etc.). For maintaining data about the legal aspects of the parts of buildings, the country profile adds the RS_LegalSpaceBuildingUnit class, with specialization RS_PartOfBuilding, such as an apartment, garage, or business space. A part of a building is described with its number, date of registration, number of rooms, information about the part of the building is located (basement, ground floor, first floor, second floor), and of the type of use of the business space.

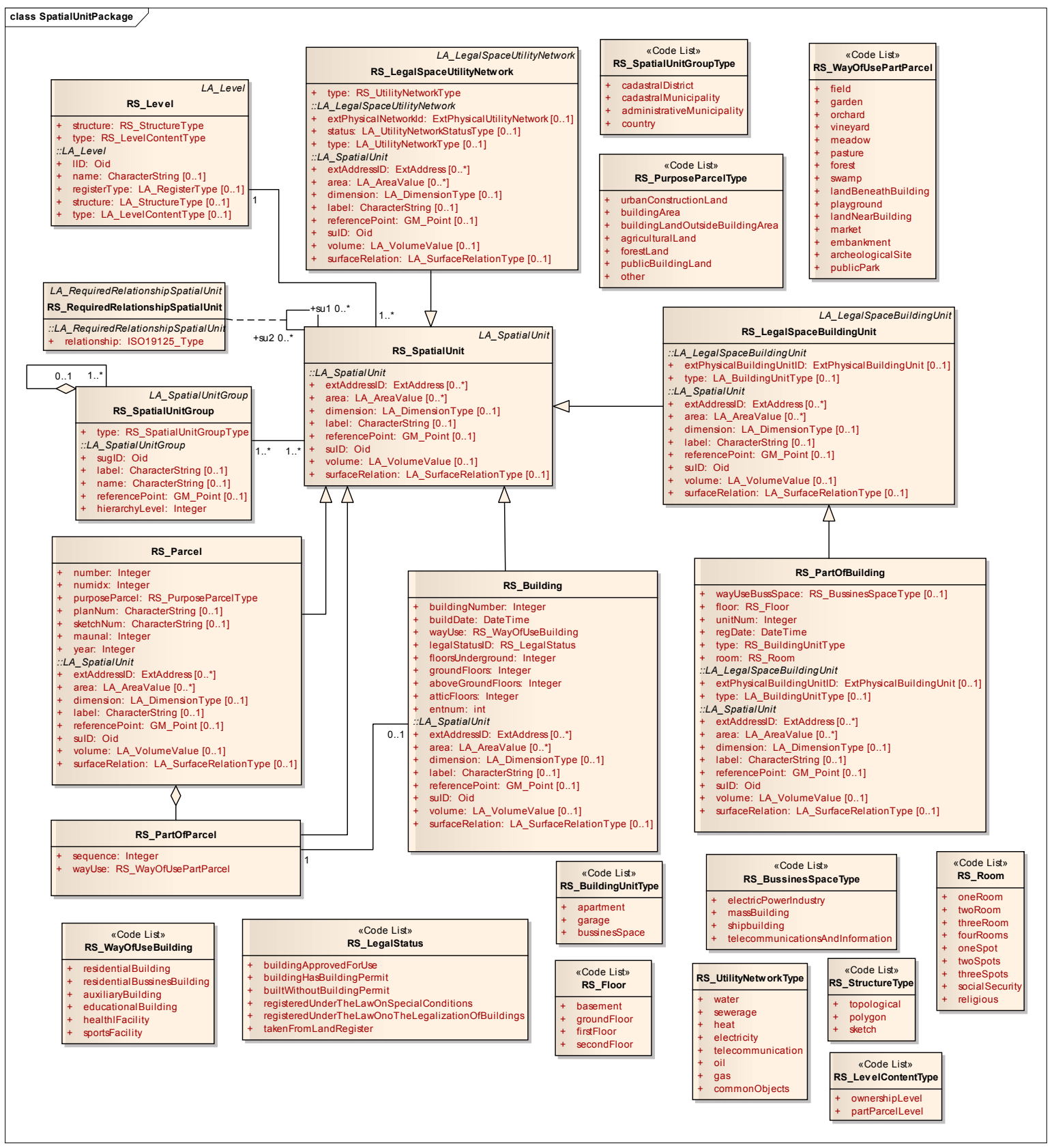

Figure 10. Spatial unit package of the Serbian profile.

The country profile allows the joining of the real estate and utility network cadastre data as required by the Law by introducing the RS_LegalSpaceUtilityNetwork class. The utility network cadastre is a register of the utility network lines together with their rights and restrictions. The types of utility networks are defined within the RS_UtilityNetworkType code list. One type refers to common utility network objects, which are in the current utility network cadastre, used to keep data about 
underground passages that belong to the real estate cadastre. With the proposed country profile, this can be corrected.

In the real estate cadastre, buildings are normally located within the parcel. Topological relationships between parcel and building can be verified by implementing the ISO 10125-2 standard. Figure 11a shows an example of parcel 1030/2 with one building. An instance of the RS_RequredRelationshipSpatialUnit class was created for the purpose of achieving a topological relationship between the parcel and the building (Figure 12).

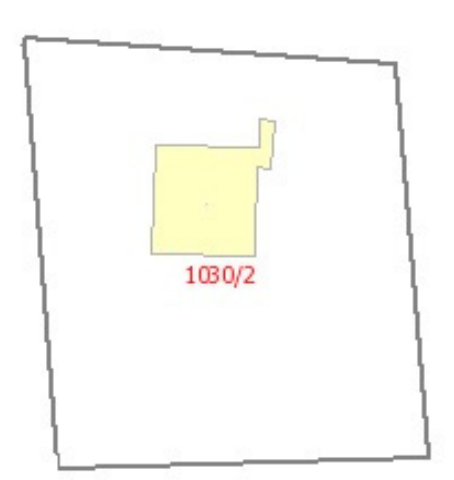

(a)

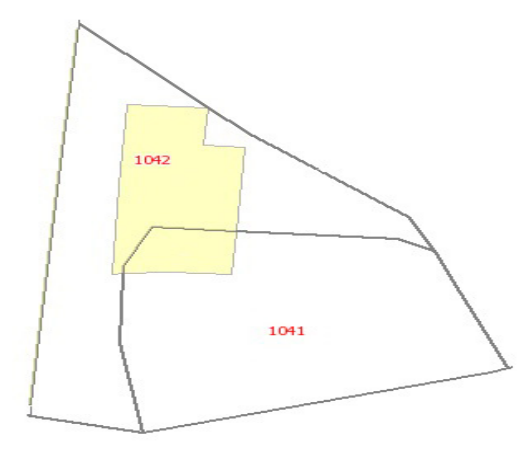

(b)

Figure 11. (a) Building within a parcel; and (b) building partly on another parcel.

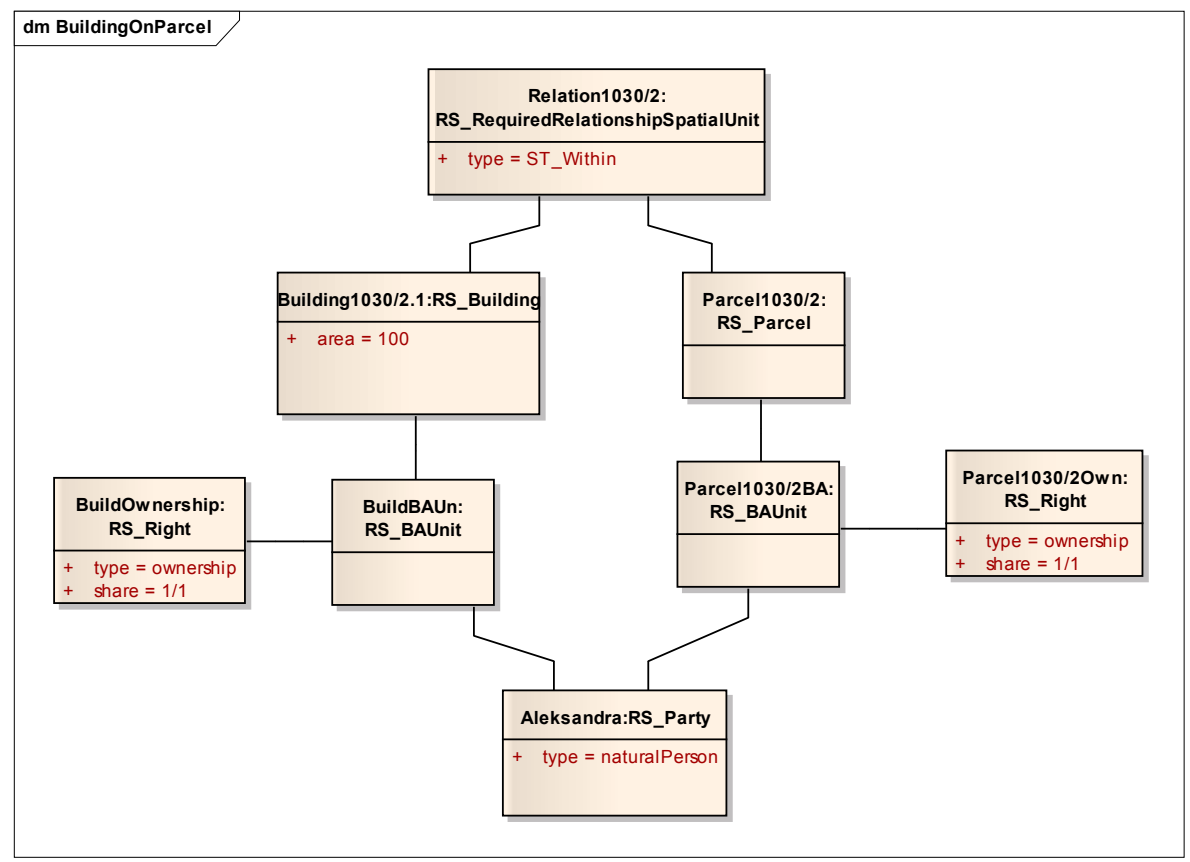

Figure 12. An instance diagram of a building within a parcel.

In practice, it is not uncommon that a building is located on two or more parcels, which would occur when a building was built without all permissions, a building taken from the land register, etc. Figure $11 \mathrm{~b}$ shows a building which is on parcel 1042, but part of the building crosses parcel 1041. For the building, a notice is recorded that a part of it is located on parcel 1041. In this example, topological relationships cannot be verified by the ST_Within operation, but the connection between the basic administrative units of the building and the other parcel can be defined, using the RS_RequiredRelationshipBAUnit class (Figure 13). 


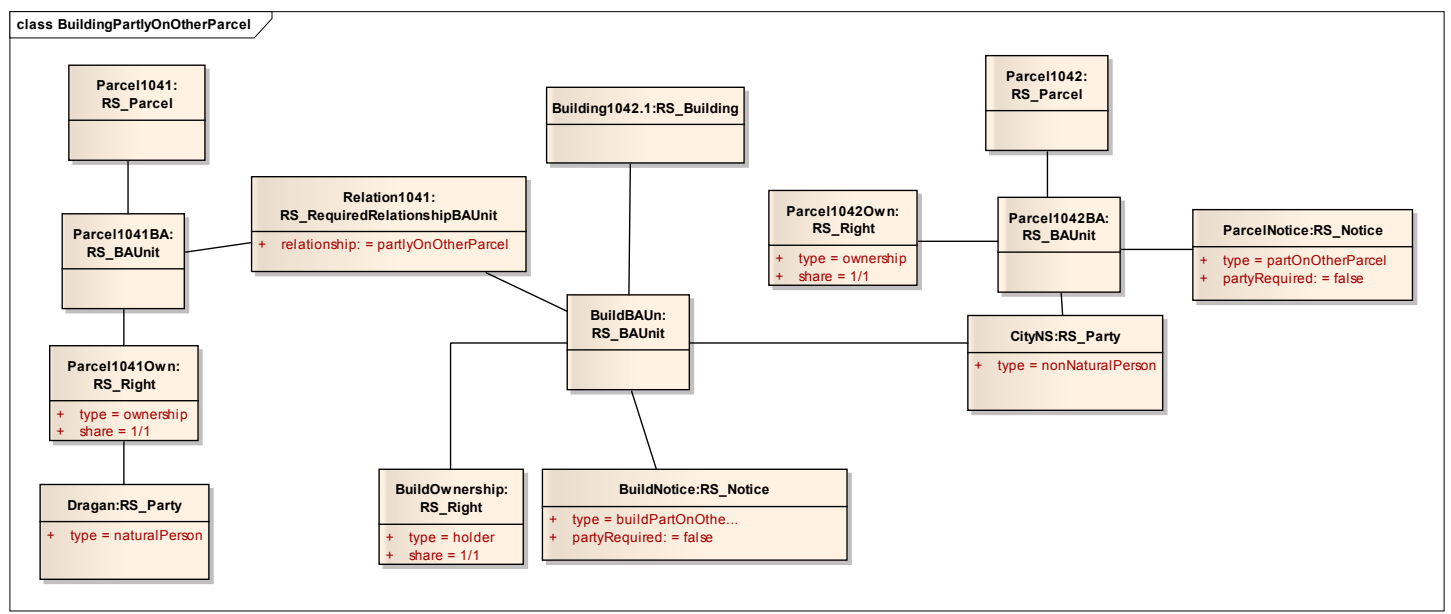

Figure 13. Instance diagram of a building partly on another parcel.

\subsubsection{Surveying and Representation Subpackage}

Classes in the surveying and representation subpackage are RS_Point, RS_SpatialSource, and RS_BoundaryFaceString (Figure 14). In the cadastral survey procedure, geodetic measurement of real property was carried out according to the actual field situation. The subject of geodetic measurement is the boundary points at the border lines of cadastral municipalities, parcels, parts of the parcel, according to the use type, and buildings, as well as other construction facilities. Data on the geometries of spatial objects can be acquired by using the polar, photogrammetric, global navigation satellite system (GNSS) method, the laser scanning method, and their combination. The individual points or complete spatial units are associated to the RS_SpatialSource class which represents a spatial source. A survey was documented with spatial sources. The types of spatial sources were defined within the RS_SpatialSourceType code list. The spatial profile for Serbia is 2D topological, so the RS_BoundaryFaceString class with GM_MultiCurve type was used for geometries.

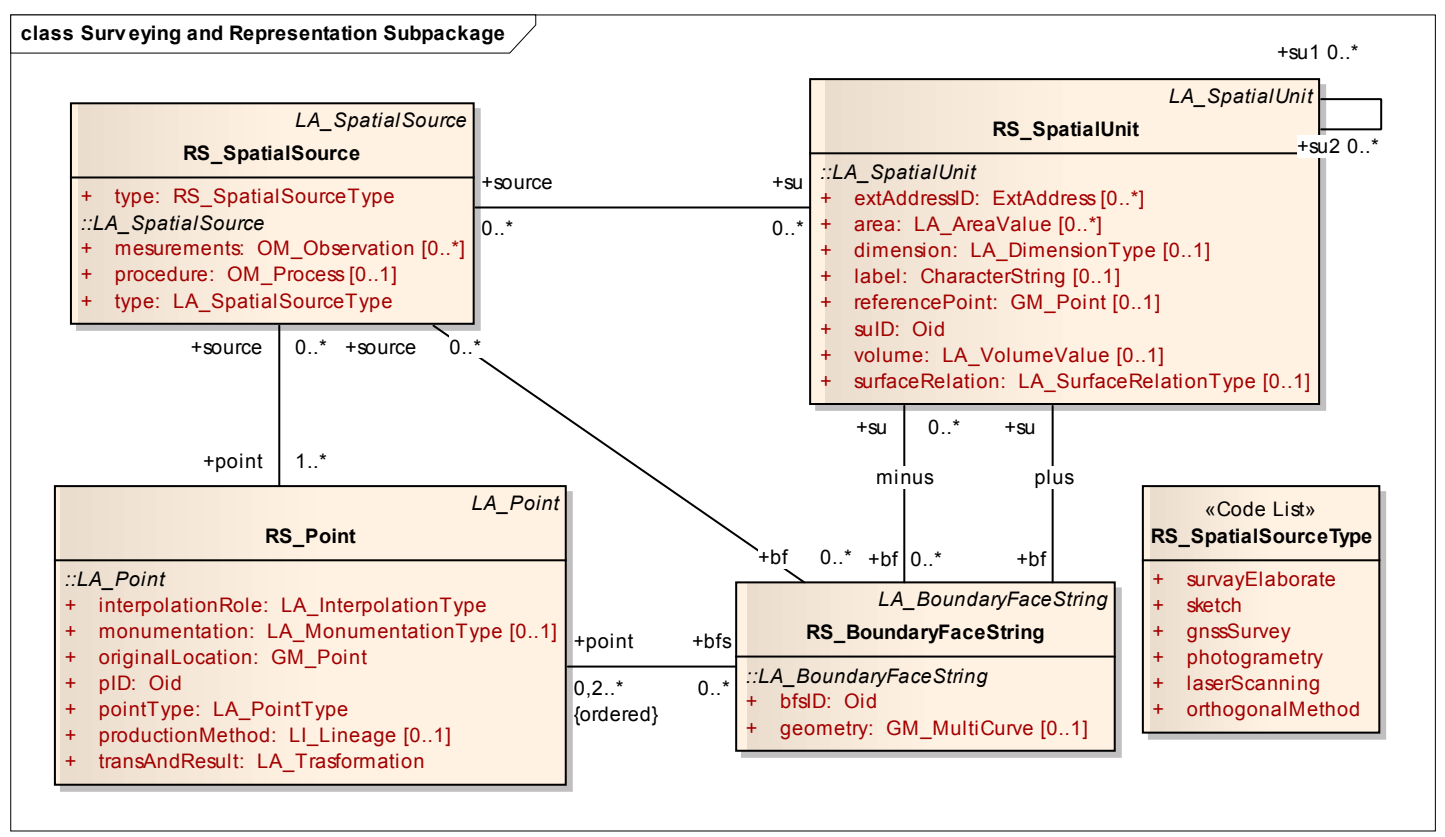

Figure 14. Surveying and representation subpackage of Serbian profile. 


\subsubsection{Conformity to LADM}

The abstract test suite, defined in Annex A of the ISO 19152 standard, specifies the requirements that the development of the country profile has to meet in order to conform to this standard. Three conformance levels are specified per (sub)package: Level 1 (low level), Level 2 (medium level), and Level 3 (high level). A low level of conformance implies that there is at least one class in the country profile that is conformant with the definition of the following classes: LA_AdministrativeSource, LA_Party, LA_RRR, LA_Right, LA_BAUnit, and LA_SpatialUnit. The medium level refers to classes LA_GroupParty, LA_PartyMember, LA_Restriction, LA_SpatialUnitGroup, LA_Level, LA_Point, LA_SpatialSource, LA_BoundaryFaceString, and the corresponding code lists. The high level involves the introduction of classes LA_Responsibility, LA_RequiredRelationshipBAUnit, LA_LegalSpaceBuildingUnit, LA_LegalSpaceUtilityNetwork, LA_RequiredRelationshipSpatialUnit, and LA_BoundaryFace.

Table 1 shows the mapping of the Serbian conceptual model, LADM classes, and the resulting Serbian country profile classes. The level of conformance to LADM is also shown. The Serbian country profile conforms to all classes from the low and medium levels, and to four of the six classes from the high level of conformance.

Table 1. LADM conformance and mapping table for the Serbian country profile.

\begin{tabular}{|c|c|c|c|}
\hline $\begin{array}{c}\text { Serbian Conceptual } \\
\text { Data Model }\end{array}$ & LADM Class & Serbian Profile Class & $\begin{array}{c}\text { Conformance } \\
\text { Level }\end{array}$ \\
\hline Case & LA_Source & RS_Source & 1 \\
\hline \multicolumn{4}{|c|}{ Party package } \\
\hline Parties & LA_Party & RS_Party & 1 \\
\hline- & LA_GroupParty & RS_GroupParty & 2 \\
\hline- & LA_PartyMember & RS_PartyMember & 2 \\
\hline \multicolumn{4}{|c|}{ Administrative Package } \\
\hline- & LA_RRR & RS_RRR & 1 \\
\hline Rights & LA_Right & RS_Right & 1 \\
\hline Restrictions & LA_Restriction & RS_Restriction & 2 \\
\hline Restrictions & LA_Restriction & RS_Notice & 2 \\
\hline Restrictions & LA_Restriction & RS_Ēasement & 2 \\
\hline- & LA_Responsibility & - & - \\
\hline RealEstateFolio & LA_BAUnit & RS_BAUnit & 1 \\
\hline Restrictions & LA_Mortgage & RS_Mortgage & 2 \\
\hline Case & LA_AdministrativeSource & RS_AdministrativeSource & 1 \\
\hline- & LA_RequredRelationshipBAUnit & RS_RequredRelationshipBAUnit & 3 \\
\hline \multicolumn{4}{|c|}{ Spatial Unit Package } \\
\hline RealEstate & LA_SpatialUnit & RS_SpatialUnit & 1 \\
\hline Parcel & LA_SpatialUnit & RS_Parcel & 1 \\
\hline PartOfParcel & LA_SpatialUnit & RS_PartOfParcel & 1 \\
\hline Building & LA_SpatialUnit & RS_Building & 1 \\
\hline CadastralMunicipality & LA_SpatialUnitGroup & RS_SpatialUnitGroup & 2 \\
\hline PartOfBuilding & LA_LegalSpaceBuildingUnit & RS_PartOfBuilding & 3 \\
\hline Pipeline & LA_LegalSpaceUtilityNetwork & RS_LegalSpaceUtilityNetwork & 3 \\
\hline- & LA_Level & RS_Level & 2 \\
\hline- & LA_RequredRelationshipSpatialUnit & RS_RequredRelationshipSpatialUnit & 3 \\
\hline \multicolumn{4}{|c|}{ Surveying and Representations Subpackage } \\
\hline- & LA_Point & RS_Point & 2 \\
\hline Case & LA_SpatialSource & RS_SpatialSource & 2 \\
\hline- & LA_BoundaryFaceString & RS_BoundaryFaceString & 2 \\
\hline- & LA_BoundaryFace & - & - \\
\hline
\end{tabular}

\section{Discussion and Possibilities for Implementation of 3D Cadastre in Serbia}

Current law and the national strategy are looking at measures to overcome the mentioned problems in the information system and do not mention any possible introduction of a 3D component to the cadastre. From the perspective of the Law, our cadastral registration method is sufficient for registering the ownership rights of the buildings in its 2D structure. However, the 2D registration system is facing limitations due to the increasing construction of buildings with more complex 
structures and the need is growing for the registration of complex ownership rights. In Serbia, many such cases exist, for which different workarounds are used in order for the complex rights to fit into the 2D cadastre. In some cases, neither buildings nor rights have been recorded in the cadastre. In other cases, the data in 2D differ from the appearance of the building in reality, and only a notice has been recorded to indicate the existence of a real property. The overview of some of these situations will be given in the following text.

Figure 15a shows the underground passage below the road in the center of Novi Sad. A number of shops and stores exist in the underground passage. The real estate cadastre only keeps the data about road above the underground passage and the rights to it, while the data about the passage and its rights are not recorded, as shown on the cadastral map (Figure 15b). The data on the underground passage are recorded in the utility network cadastre. According to the Law, the data on all underground buildings should be a part of the real estate cadastre.

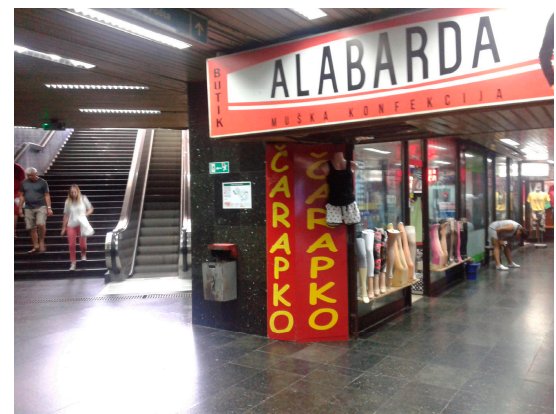

(a)

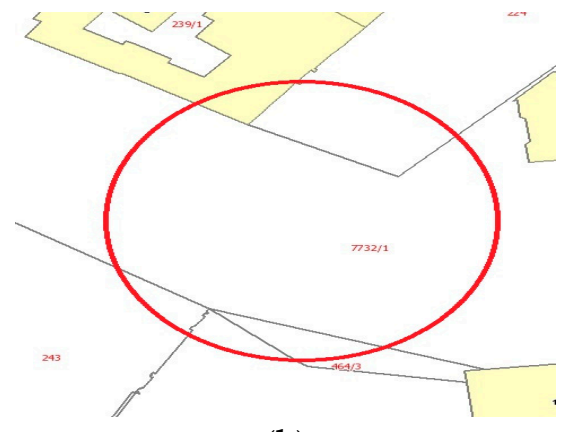

(b)

Figure 15. (a) Underground passage; and (b) the cadastral map for the area of the underground passage.

Figure 16a shows skyscrapers, named Geneks Towers in Belgrade, which are connected on the 26th floor with a two-story passage. A rotating restaurant, currently in the reconstruction stage, is located on the top of one of the towers. On the 2D cadastral map, the towers are shown as two separate buildings, and they are recorded as such in the information system (Figure 16b). The notice on one of the towers says that a business space above 26th floor exists, while parts of the building are not listed.

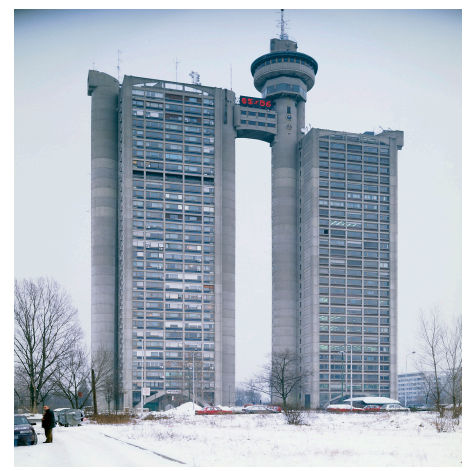

(a)

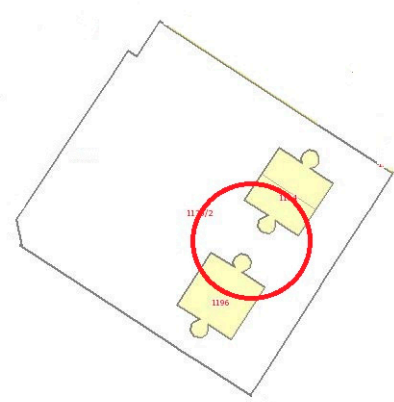

(b)

Figure 16. (a) Geneks Towers (adapted from [29]); and (b) the cadastral map for Geneks Towers.

Another example of overlapping rights that the 2D cadastre cannot properly record is the Petrovaradin fortress. It is located on the bank of the Danube River near the city of Novi Sad. The real estate cadastre records the parcels and buildings that are located on the fortress. Figure 17a shows the fortress itself and Figure 1 shows the cadastral map of the entire area of the fortress. It is divided into many small parcels on top of the fortress, while the fortress itself is not located on the parcel, and it is 
not recorded as an object (building). However, this is an excellent example of the complexity of the concept of a "building".

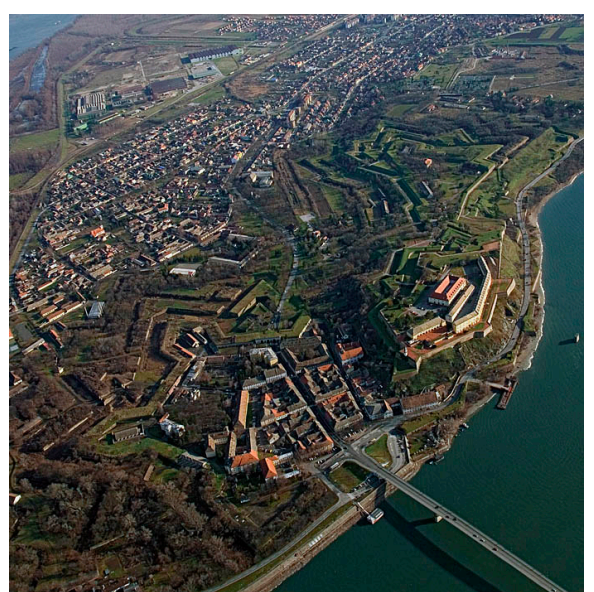

(a)

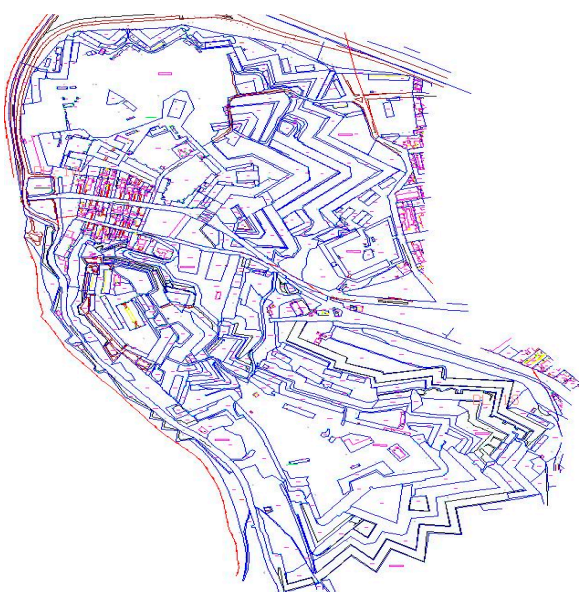

(b)

Figure 17. (a) The Petrovaradin fortress (adapted from [30]); and (b) cadastral map of the Petrovaradin fortress.

The Petrovaradin fortress, an exceptional achievement of the fortification architecture of the eighteenth century, is one of the most complex, largest, and best-preserved baroque artillery bastion fortresses in Southeast Europe. Today's fortress extends over an area of over 105 ha, with the total length of the outer defense line of $5500 \mathrm{~m}$, and a complex system of underground military tunnels and galleries. The underground galleries are made in four levels, interconnected by a series of horizontal and vertical communication corridors. The length of these communications and underground chambers is over $16,000 \mathrm{~m}$. The Petrovaradin fortress was completely demilitarized in the mid-twentieth century. It was proclaimed to be a historical monument and a cultural asset of great importance, was placed under state protection, and assigned to civilian use. On the fortress and in the underground tunnels and chambers, the Museum and Archives of Novi Sad, hotels and restaurants, ateliers and galleries of fine artists, an arts academy, astronomical observatory, planetarium, etc. are located [31]. Figure 18 shows a sketch displaying how the tunnels and chambers are distributed within the fortress (Figure 18a), followed by images of the underground military galleries (Figure 18b), and art studios (Figure 18c), that are now located inside the fortress. The fortress is owned by the city of Novi Sad, while the real properties on it and in it are leased. The leases are initiated by a lease contract, and according to the Law, the lease should be registered in the real estate cadastre. Due to the lack of records on the real property itself within the fortress, the legal right of tenants to enter their contract into cadastral records is denied.

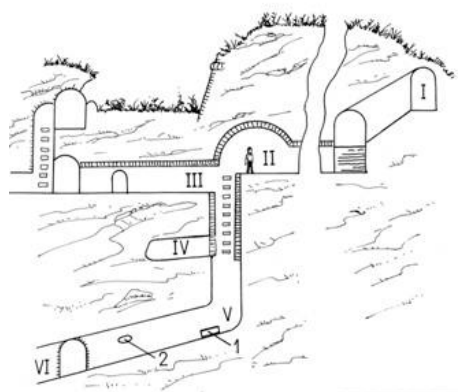

(a)

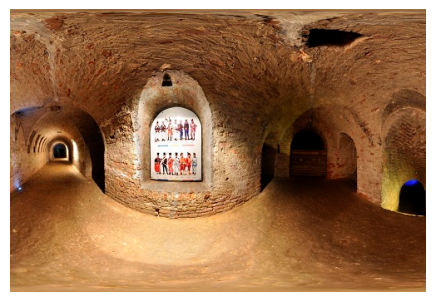

(b)

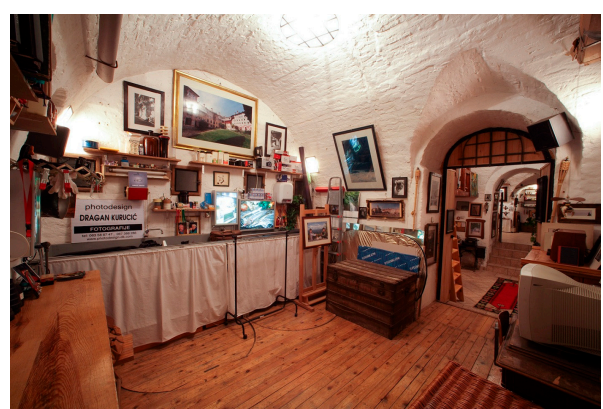

(c)

Figure 18. (a) Sketch of an underground tunnel and chambers (adapted from [32]); (b) underground tunnels (adapted from [33]); and (c) underground art gallery of Dragan Kurucić (adapted from [34]). 
In the case of the Petrovaradin fortress, the problem of recording the rights to the tunnels and chambers can be solved by using the RequiredRelationshipBAUnit class in the country profile. Due to the inability of the 2D cadastre to record overlapping rights in $3 \mathrm{D}$, and because the area of the fortress is divided into numerous parcels, data on the fortress itself, and its internal parts, are not recorded in the cadastre. If the land on which the fortresses is located is declared a large parcel, then duplication of the cadastral area would occur because the area on top of the fortress is divided into many small parcels within which the hotels, restaurants, galaries, and other buildings are located. Merging all the small parcels into one big parcel is also not a good solution, since there are many buildings located on the fortress. A solution can be reached if the fortress is presented as a building, and the tunnels and chambers as parts of the building. For each of them, the basic administrative unit can be defined. The fortress can be associated with the "baunits" of all the small parcels by using an instance of the RS_RequiredRelationshipBAUnit with the partlyOnOtherParcel type. In this way, the total area of the cadastral municipality remains the same, and the problem of recording rights on the fortress and its special parts is solved. However, the problem of recording data on the fortress in the cadastral map remains. Figure 19 shows the registration of ownership and the lease of the underground chambers.

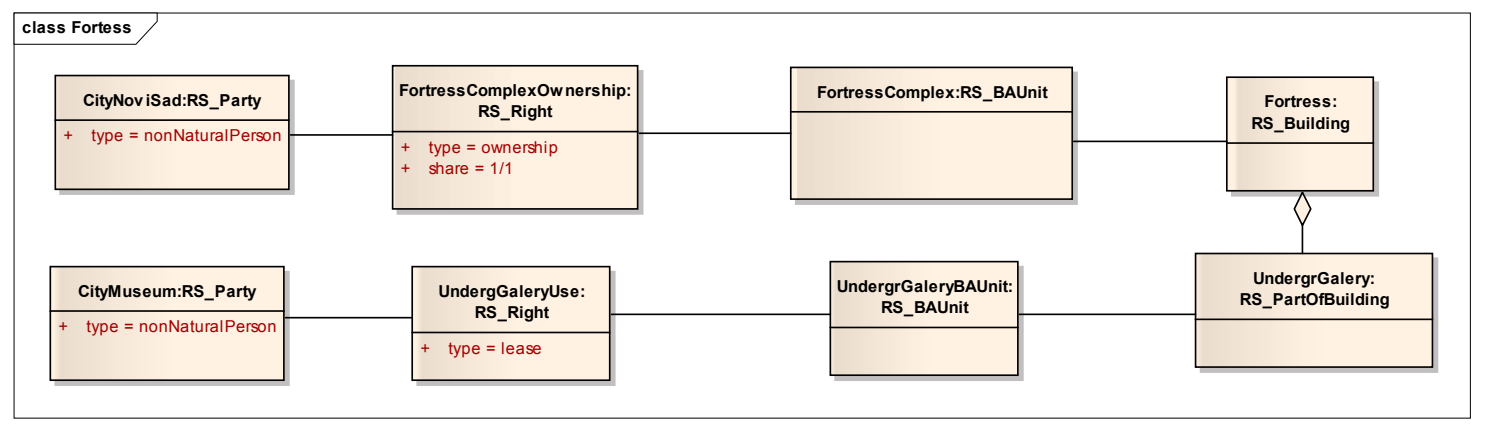

Figure 19. Instance diagram of registering rights on underground gallery.

Based on the previous cases, we concluded that a need for the introduction of 3D into the Serbian cadastre exists. The International Federation of Surveyors (FIG) joint commission 3 and 7 Working Group on 3D Cadastres created a set of questionnaires and sent them to the working group participants to make a world-wide inventory of the status of 3D cadastres at the current moment and the plans for the future. From the questionnaire filled by Serbian experts [35], we concluded that the work on the 3D cadastre would not be planned by 2018. However, if the measures of the Strategy are implemented, it would be possible to consider it in the near future. The FIG Working group on 3D Cadastre proposes several options for creating a 3D model of the cadastre, so that different countries can choose different optimal solutions, depending on the actual situation and conditions: minimalistic, topographic, polyhedral legal, non-polyhedral legal, and topological [36]. The criteria for applying these solutions are based on four key areas of the 3D cadastre: Legal aspects of 3D, initial registration of the 3D parcel, 3D data management, and visualization of 3D objects. These criteria should be further analyzed to chose the right solution for the Serbian cadastre.

ISO 19152 provides support for 3D representations and 3D registration of rights, so the creation of a country profile for Serbia is a starting point toward the development of a 3D cadastre. Given the existence of buildings with overlapping rights and restrictions in 3D, due to their shape or position, considering the expansion of the spatial profile with 3D geometries in such situations is necessary. In Serbia, the 2D cadastre is still not fully formed but it should not be an obstacle to introducing 3D into the cadastre. The availability of production and data collection technologies enables collecting 3D data for these buildings in CityGML format. It is possible to map LADM, especially its representation of legal spaces, to and encode as a CityGML Application Domain Extension (ADE) [37]. Building Information Modeling (BIM) is used for planning, designing, construction, and management of modern residential and business buildings and infrastructure. These data could also be used in the cadastre 
for the registration of real properties, rights, and restrictions [38,39]. One way of doing this is to introduce external links, with which a 3D view of data could be shown. For example, by creating an association between the RS_Building class from the country profile and AbstractBuilding from the CityGML conceptual model [40]. Another and more complex way would be to expand the Serbian country profile with the RS_BoundaryFace class, and to transform 3D data in this model. In both ways, using the 2D model for simple rights situations, and 3D model for more complex situations and buildings which already have geometries in 3D, would be possible. Whether 3D buildings are stored in the database or not, the consistent maintenance of 3D data should be considered a high priority.

\section{Conclusions}

Considering the cadastral information system in Serbia is outdated and not satisfactorily functional, there is a requirement, at the country level by the Government, to replace it and develop a new one. We propose that the new system be based on LADM, and have proven our proposal by developing a LADM-based domain model of the cadastre in Serbia. The current Serbian cadastral data organization fits into a LADM-based data model without losing any relevant information, and the conformance with LADM was determined. Using LADM will not only provide interoperability, but also international experience with the goal of providing better service to end users by providing more accurate data in a timely manner, which is not the case with the current system.

The authors analyzed the possibilities of developing the aspects of a 3D cadastre. Future work will include a thorough analysis of all relevant use cases, data acquisition techniques, and possible formats for creation, submission, and registration of 3D spatial units and their rights, storage, and analyses of the 3D data, 3D cadastral visualization, semantics, etc. The aim is to lay the foundation for the development of a legal framework and formal procedures that will enable the use of modern geospatial technologies, which are gaining momentum in this country, but are not yet fully accepted in regular practice.

Author Contributions: Aleksandra Radulović conceived the outline of the article and is the first author of the article. She developed the domain model based on the experience gained through collaboration with Serbian Republic Geodetic Authority on the cadastral information system development. Dubravka Sladić is the co-author of Sections 2-4 and author of Sections 1 and 5. She also helped develop the model through thorough analysis of the data model and system currently in use. Miro Govedarica was the project lead and influenced the work by suggesting the key points.

Conflicts of Interest: The authors declare no conflict of interest.

\section{References}

1. Land Administration Guidelines. United Nations: New York, NY, USA; Geneva, Switzerland, 1996. Available online: http://www.unece.org/fileadmin/DAM/hlm/documents/Publications/land. administration.guidelines.e.pdf (accessed on 25 August 2017).

2. Dale, P.; McLaughlin, J. Land Administration; Oxford University Press: Oxford, UK, 1999.

3. Sladić, D.; Radulović, A.; Govedarica, M. Cadastral Records in Serbian Land Administration. In Proceedings of the FIG Working Week 2017, Helsinki, Finland, 29 May-2 June 2017.

4. ISO 19152:2012 Geographic information—Land Administration Domain Model (LADM). Available online: https:/ / www.iso.org/standard/51206.html (accessed on 24 August 2017).

5. Lemmen, C.; Van Oosterom, P.; Bennett, R. The Land Administration Domain Model. Land Use Policy 2015, 49, 535-545. [CrossRef]

6. Van Oosterom, P.; Lemmen, C. The Land Administration Domain Model (LADM): Motivation, standardisation, application and further development. Land Use Policy 2015, 49, 527-534. [CrossRef]

7. Kalantari, M.; Dinsmore, K.; Urban-Karr, J.; Rajabifard, A. A roadmap to adopt the Land Administration Domain Model in cadastral information system. Land Use Policy 2015, 49, 552-564. [CrossRef]

8. Stoter, J.; van Oosterom, P. 3D Cadastre in an International Context. Legal, Organizational, and Technological Aspects; CRC Press: Boca Raton, FL, USA, 2006. 
9. Van Oosterom, P. Research and development in 3D cadastres. Comp. Environ. Urban Syst. 2013, 40, 1-6. [CrossRef]

10. Bydłosz, J. The application of the Land Administration Domain Model in building a country profile for the Polish cadastre. Land Use Policy 2015, 49, 598-605. [CrossRef]

11. Janečka, K.; Souček, P. A Country Profile of the Czech Republic Based on an LADM for the Development of a 3D Cadastre. ISPRS Int. J. Geo-Inf. 2017, 6, 143. [CrossRef]

12. Vučić, N.; Markovinović, D.; Mičević, B. LADM in the Republic of Croatia-making and testing country profile. In Proceedings of the 5th FIG International Land Administration Domain Model Workshop 2013, Kuala Lumpur, Malaysia, 24-25 September 2013.

13. Mađer, M.; Matijević, H.; Roić, M. Analysis of possibilities for linking land registers and other official registers in the Republic of Croatia based on LADM. Land Use Policy 2015, 49, 606-616. [CrossRef]

14. Psomadak, S.; Dimopoulou, E.; Van Oosterom, P. Model driven architecture engineered land administration in conformance with international standards-illustrated with the Hellenic Cadastre. Open Geospat. Data Softw. Stand. 2016. [CrossRef]

15. Stoter, J.; Ploeger, H.; van Oosterom, P. 3D cadastre in the Netherlands: Developments and international applicability. Comp. Environ. Urban Syst. 2013, 40, 56-67. [CrossRef]

16. Drobež, P.; Fras, M.K.; Ferlan, M.; Lisec, A. Transition from 2D to 3D real property cadastre: The case of the Slovenian cadastre. Comp. Environ. Urban Syst. 2017, 62, 125-135. [CrossRef]

17. Lee, B.; Kim, T.; Kwak, B.; Lee, Y.; Choi, J. Improvement of the Korean LADM country profile to build a 3D cadastre model. Land Use Policy 2015, 49, 660-667. [CrossRef]

18. Official Gazette of the Republic of Serbia. The Law on State Survey and Cadastre. 2009. Available online: http:/ / paragraf.rs / propisi/zakon_o_drzavnom_premeru_i_katastru.html (accessed on 24 August 2017).

19. Official Gazette of the Republic of Serbia. Amendments to the Law on State Survey and Cadastre. 2015. Available online: http:/ / www.rgz.gov.rs/web_preuzimanje_datotetka.asp?LanguageID=3\&FileID=1793 (accessed on 24 August 2017).

20. Official Gazette of the Republic of Serbia. The Rulebook on Cadastre Survey and Real Estate Cadastre. 2016. Available online: http: / / www.rgz.gov.rs / web_preuzimanje_datotetka.asp?LanguageID=3\&FileID=1840 (accessed on 24 August 2017).

21. Official Gazette of the Republic of Serbia. The Strategy of Measures and Activities for Increasing the Quality of Services in the Field of Geospatial Data and Registration of Real Property Rights in the Official State Records. 2017. Available online: http://www.rgz.gov.rs/web_preuzimanje_datotetka.asp?LanguageID= 3\&FileID=2444 (accessed on 25 August 2017).

22. Official Gazette of the Republic of Serbia. The Law on State Survey and Cadastre and Registration of Rights on Real Estates. 1992. Available online: http:/ / notarisrbija.rs/wp-content/uploads/2014/09/zakon_ katastar_nepokretnosti.pdf (accessed on 24 August 2017).

23. Official Journal of the European Union. Directive 2007/2/EC of the European Parliament and of the Council of 14 March 2007 Establishing an Infrastructure for Spatial Information in the European Community. Available online: https: / inspire.ec.europa.eu/documents/directive-20072ec-european-parliament-andcouncil-14-march-2007-establishing (accessed on 25 August 2017).

24. Official Gazette of the Republic of Serbia. The Strategy of Establishing a Spatial Data Infrastructure in the Republic of Serbia for the Period 2010-2012. Available online: http:/ / www.geosrbija.rs/DownloadFile.aspx? fileID=51 (accessed on 25 August 2017).

25. Radulović, A. Domain and Service Model for Real Estate Cadastre Geoinformation System. Ph.D. Thesis, Faculty of Technical Sciences, Novi Sad, Serbia, 16 July 2015.

26. Radulović, A.; Sladić, D.; Govedarica, M. Serbian Profile of the Land Administration Domain Model. In Proceedings of the FIG Working Week 2017, Helsinki, Finland, 29 May-2 June 2017.

27. Sladić, D.; Govedarica, M.; Pržulj, Đ.; Radulović, A.; Jovanović, D. Ontology for real estate cadastre. Surv. Rev. 2013, 45, 357-371. [CrossRef]

28. Official Gazette of the Republic of Serbia. The Law on Property Relations in Serbia. Available online: http: / / paragraf.rs / propisi / zakon_o_osnovama_svojinskopravnih_odnosa.html (accessed on 25 August 2017).

29. Photo by Błażej Pindor. Available online: https:/ / commons.wikimedia.org/w /index.php?curid=7686393 (accessed on 27 August 2017). 
30. Photo from the Official Page of the Institute for the Protection of Cultural Monuments is Novi Sad. Available online: http:/ / www.zzskgns.rs/wp-content/uploads/2014/07/IMG_0048xcxxVECAxxcisto.jpg (accessed on 27 August 2017).

31. Institute for the Protection of Cultural Monuments is Novi Sad. Available online: http://www.zzskgns.rs / (accessed on 25 August 2017).

32. The Official Site of Researcher and Inventor Veljko Milković. Available online: http:/ / www.veljkomilkovic. com/Images/Podzemlje_clip_image002.jpg (accessed on 27 August 2017).

33. The Official Site of Panacomp Wonderland Travel. Available online: http://www.panacomp.net/wpcontent/uploads/2016/03/Vojne-galerije-site-1.jpg?x23386 (accessed on 27 August 2017).

34. Photo by Dragan Kurucić. Available online: http:/ /www.panacomp.net/wp-content/uploads/2016/05/ featured-S-17-2.jpg?x23386 (accessed on 27 August 2017).

35. Questionnaire 3D-Cadastres: Status September 2014 Serbia. Available online: http://www.gdmc.nl/ 3dcadastres/participants/3D_Cadastres_Serbia2014.pdf (accessed on 25 August 2017).

36. FIG Joint Commission 3 and 7 Working Group on 3D Cadastres. Available online: http:/ /www.gdmc.nl/ 3dcadastres/realization/ (accessed on 25 August 2017).

37. Rönsdorf, C.; Wilson, D.; Stoter, J. Integration of Land Administration Domain Model with CityGML for 3D Cadastre. In Proceedings of the 4th International Workshop on 3D Cadastres, Dubai, UAE, 9-11 November 2014.

38. Oldfield, J.; van Oosterom, P.; Quak, W.; van der Veen, J.; Beetz, J. Can Data from BIMs be Used as Input for a 3D Cadastre? In Proceedings of the 5th International FIG 3D Cadastre Workshop, Athens, Greece, 18-20 October 2016.

39. Ho, S.; Rajabifard, A.; Roić, M. Towards 3D-enabled urban land administration: Strategic lessons from the BIM initiative in Singapore. Land Use Policy 2016, 57, 1-10. [CrossRef]

40. Góźdź, K.; Pachelski, W.; van Oosterom, P.; Coors, V. The Possibilities of Using CityGML for 3D Representation of Buildings in the Cadastre. In Proceedings of the 4th International Workshop on 3D Cadastres, Dubai, UAE, 9-11 November 2014.

(C) 2017 by the authors. Licensee MDPI, Basel, Switzerland. This article is an open access article distributed under the terms and conditions of the Creative Commons Attribution (CC BY) license (http://creativecommons.org/licenses/by/4.0/). 